\title{
The comparison of laparoscopy, shock wave lithotripsy and retrograde intrarenal surgery for large proximal ureteral stones
}

\author{
M.D. Ufuk Ozturk, MD; ${ }^{*}$ Nevzat Can Şener, MD; ${ }^{*}$ H.N. Goksel Goktug, MD; ${ }^{*}$ Adnan Gucuk, MD; ${ }^{\dagger}$ \\ Ismail Nalbant, MD;s M. Abdurrahim Imamoglu, $M D^{*}$
}

*Ministry of Health, Ankara Dişkapı Yıldıım Beyazit Education and Research Hospital, Department of Urology, Ankara, Turkey; †Department of Urology, AlBU School of Medicine, Bolu, Turkey; §Ministry of Health, Yenimahalle State Hospital, Department of Urology, Ankara, Turkey

Cite as: Can Urol Assoc J 2013;7(11-12):e673-6. http://dx.doi.org/10.5489/cuaj.346

Published online November 8, 2013.

\section{Abstract}

Introduction: In this study we compare the success rates and complication rates of shock wave lithotripsy (SWL), laparoscopic, and ureteroscopic approaches for large (between 1 and $2 \mathrm{~cm}$ ) proximal ureteral stones.

Methods: In total, 151 patients with ureteral stones between 1 and $2 \mathrm{~cm}$ in diameter were randomized into 3 groups $(52 \mathrm{SWL}$, 51 laparoscopy and 48 retrograde intrarenal surgery [RIRS]). The groups were compared for stone size, success rates, and complication rates using the modified Clavien grading system.

Results: Stone burden of the groups were similar $(p=0.36)$. The success rates were $96 \%, 81 \%$ and $79 \%$, respectively in the laparoscopy, SWL, and ureteroscopy groups. The success rate in laparoscopy group was significantly higher $(p<0.05)$. When these groups were compared for complication rates, RIRS seemed to be the group with the lowest complication rates $(4.11 \%)(p<0.05)$. SWL and laparoscopy seem to have similar rates of complication $(7.06 \%$ and $7.86 \%$, respectively, $p=0.12$ ).

Interpretation: To our knowledge, this is the first study to compare the results of laparoscopy, SWL and RIRS in ureteral stones. Our results showed that in management of patients with upper ureteral stones between 1 and $2 \mathrm{~cm}$, laparoscopy is the most successful method based on its stone-free rates and acceptable complication rates. However, the limitations of our study are lack of hospital stay and cost-effectiveness data. Also, studies conducted on larger populations should support our findings. When a less invasive method is the only choice, SWL and flexible ureterorenoscopy methods have similar success rates. RIRS, however, has a lower complication rate than the other approaches.

\section{Introduction}

Upper ureteral stones, which are hard to treat, are frequently encountered in daily practice. For treatment, the most effective and the safest approach should be chosen. Upper ure- teral stones can be managed by various approaches. There is no gold standard treatment for stones between 1 and $2 \mathrm{~cm}$. Even though some researchers recommend extracorporeal shock wave lithotripsy (SWL) as first-line treatment, ${ }^{1}$ it has a $40 \%$ success rate in larger proximal ureteral calculi. ${ }^{2}$ With the common use of flexible devices in urology, ureteroscopy has gained popularity in the treatment of upper ureteral stones. For stones larger than $1 \mathrm{~cm}$ and fully obstructing the passage in the ureter, open or laparoscopic surgery may be an option with success rates up to $100 \% .^{1}$ In recent years, some authors have published their data on the laparoscopic approach and have recommended its use for its high success and low complication rates. ${ }^{3}$

This study compares the success and complication rates of SWL and laparoscopic and ureteroscopic approaches for proximal ureteral calculi between 1 and $2 \mathrm{~cm}$.

\section{Methods}

After Institutional Review Board approval, we enrolled 150 patients who had ureteral stones between 1 and $2 \mathrm{~cm}$ in the study; they were randomized into 3 groups by an online randomization program (52 for SWL, 51 for laparoscopy, and 48 for retrograde intrarenal surgery (RIRS). ${ }^{4}$ All patients provided written informed consent. We excluded patients under 18 years old with previously managed calculi or multiple stones and/or with solitary kidney or ureteropelvic junction obstruction. Stone clearance was assessed intraoperatively and with postoperative or post-procedure $x$-rays and urinary ultrasound after 3 months. At 3 months, the patients were evaluated by a physician blinded for the treatment method. A stone-free status at 3 months or having clinically insignificant sized stones $(<4 \mathrm{~mm})$ were considered successful. All success rates were determined by a single session of the operation and, at most, 3 sessions of SWL.

Electrohydraulic extracorporeal lithotripter (Multimed Classic, Elmed, Ankara, Turkey) was used for SWL (in each 
lithotripsy session, 2.500 to 3.500 shocks were given at 14 to $17 \mathrm{kv}$ ), and flexible ureterorenoscope (Olympus URFP5, Tokyo, Japan) and holmium laser (Ho:YAG Laser; Dornier MedTech, Munich, Germany) for flexible ureterorenoscopy. The patients in the SWL group underwent 3 courses of SWL therapy at most. Each procedure was performed by a single surgeon.

The groups were compared for stone size, success rates, and complication rates using the modified Clavien grading system. We tallied patient characteristics (Table 1).

Statistical analyses were performed using the Statistical Package for Social Sciences version 20.0 software (SPSS Inc, Chicago, IL). In addition to the frequency and percentage distributions of the data, Student's t-test was used in group comparisons, and the chi-square test was used for comparisons of variables between categorical data. A value of $p<0.05$ was considered statistically significant.

A power analysis based on previous studies ${ }^{2,3}$ showed that groups with an average of 48 patients each would be required to demonstrate the outcomes with a Type I error of 0.05 .

\section{Results}

In total, 52 patients were managed with SWL. The mean stone size of SWL group was $13.2 \mathrm{~mm}( \pm 2.04)$. Fifty-one patients were managed with laparoscopy, and the mean stone size was $13.3 \mathrm{~mm}( \pm 2.06)$. Forty-eight patients were managed with RIRS and had a stone burden of $13.2 \mathrm{~mm}$ $( \pm 2.01)$. Stone burden of the groups were similar $(p=0.36)$.

The mean SWL sessions was $2.31( \pm 0.73)$. The stone-free rate of SWL group was $81 \%$. One patient in SWL group suffered from steinstrasse; 2 patients suffered from severe pain and discontinued the therapy, and 1 patient had perirenal hematoma and was treated conservatively.

Laparoscopy group had the highest stone-free rate (96\%). The success rate in this group was significantly higher than the rates of the other groups $(p<0.05)$. Conversion to open surgery was necessary in 1 patient $(2 \%)$. Because of peritoneal laceration, 1 (2\%) patient in laparoscopy group had prolonged urine discharge in need of extra hospitalization (13 days-spontaneous remission), 2 patients (4\%) developed mild fever in the first 24 hours.

RIRS group consisted of 48 patients. Of these patients, 39 had a stone-free rate of $79 \%$. One patient had grade one ureteral laceration, and 1 patient in RIRS group had postoperative fever.

Procedure outcomes were summarized in Table 2 . Complications were summarized in Table 3 according to the modified Clavien System.

\begin{tabular}{lccc}
\hline \multicolumn{4}{l}{ Table 1: Patient demographics } \\
\hline & SWL & Laparoscopy & RIRS \\
\hline Number & 52 & 51 & 48 \\
Age (range), years & $40.7(20-78)$ & $40.0(19-62)$ & $41.1(24-58)$ \\
Sex & & & \\
Male & 33 & 21 & 30 \\
Female & 19 & 30 & 18 \\
Stone position & & & \\
Left & 24 & 31 & 30 \\
Right & 28 & 20 & 18 \\
\hline SWL: shock wave lithotripsy; RIRS: retrograde intrarenal surgery. \\
\hline
\end{tabular}

\section{Discussion}

Upper ureteral stones are hard-to-treat conditions. Although the European Association of Urology (EAU) Guidelines on urolithiasis recommend SWL or ureterorenoscopy (URS) as first-line treatment, open or laparoscopic approaches are recommended for select cases. ${ }^{1}$

SWL is preferred for proximal ureteral stones larger than $1 \mathrm{~cm}$. The success of SWL on proximal ureteral stones varies between $57 \%$ and $96 \% .^{5-7}$ Because SWL is less invasive than other approaches and is an outpatient method, both patients and doctors generally consider it a first-line therapy. SWL is not a surgical procedure and is therefore considered a non-invasive approach. Nevertheless, it must be kept in mind that SWL has its own complications. The most common one is renal injury at $2.5 \% .{ }^{8}$ There are also more serious complications, such as subcapsular hematoma. ${ }^{9}$ Moreover, ruptured spleen, acute pancreatitis, and even rectorrhage are other reported complications. ${ }^{10,11}$ Another recent study has mentioned renal scarring by comparing the scintigraphic outcomes of patients who had undergone either percutaneous nephrolithotomy (PNL) or SWL. The study revealed less scarring in PNL patients. ${ }^{12}$ In the light of this information, it can be said that SWL should not be considered a noninvasive method. In this study, the success rate of SWL was $80 \%$, which is consistent with current literature. ${ }^{13,14}$ The failed cases were treated by either PNL or RIRS, but they were not included in the study. With a mean of 2.31 sessions, our complication rate was $8 \%$. One patient suffered from steinstrasse and it was managed by rigid ureteroscopy. Also, 2 patients suffering from flank pain caused by SWL discontinued the therapy. One patient suffering subcapsular hematoma was treated conservatively. The patients with failed SWL were managed by either ureteroscopy or laparoscopy. However, they were not included in the study.

If SWL treatment is not feasible, especially if there is full obstruction in the ureter, open surgery is an alternative. Open surgery has good success rates, but with its high morbidity, it is not considered a treatment alternative. ${ }^{1}$ Instead of open surgery, a laparoscopic technique with similar success and lower morbidity can be applied. ${ }^{1}$ 


\begin{tabular}{lcccc}
\hline \multicolumn{7}{l}{ Table 2. Procedure outcomes } \\
\hline & SWL $(\mathbf{n = 5 2 )})$ & $\begin{array}{c}\text { Laparoscopy } \\
(\mathbf{n}=\mathbf{5 1})\end{array}$ & RIRS $(\mathbf{n = 4 8 )}$ & $\boldsymbol{p}$ value \\
\hline Stone size & $13.2 \mathrm{~mm}$ & $13.3 \mathrm{~mm}$ & $13.2 \mathrm{~mm}$ & \\
\pm SD $(\mathrm{mm})$ & $( \pm 2.04)$ & $( \pm 2.06)$ & $( \pm 2.01)$ & $p=0.24$ \\
Success rate & $81 \%$ & $96 \%$ & $79 \%$ & $p<0.05$
\end{tabular}

SWL: shock wave lithotripsy; RIRS: retrograde intrarenal surgery; SD: standard deviation.

The first transperitoneal laparoscopic ureterolithotomy was performed by Raboy and colleagues in $1992 .{ }^{15}$ After Gaur described a retroperitoneal laparoscopic surgery facilitated by a hydraulic balloon dilatation system in 1992,16 straightforward access became available through the retroperitoneum. Thereafter, several authors have tried to replace open ureterolithotomy as a transperitoneal or retroperitoneal laparoscopic procedure for ureteral stone disease due to its minimally invasive nature. Laparoscopic surgery is a successful method considering its stone-free rates as high as $100 \% .{ }^{1}$ With its easy application to relatively larger stones, laparoscopy is one step ahead compared to SWL or flexible ureteroscopy. However, because of its higher morbidity and the need for experience, laparoscopy is not considered a first-line treatment. In our series, the success rate was $96 \%$. Two patients had to be managed by SWL after the stone migrated to the kidney, and a double J stent was inserted. The mean hospitalization was 2 days, similar to the literature. ${ }^{17}$ The mean operation time was 78 minutes for the first 30 cases and 43 minutes for the remaining cases. With minimum hemorrhage and morbidity rates, a single-session treatment is advantageous for patients. However, 1 patient managed by conservative treatment had prolonged urine discharge and had to be hospitalized for 13 days; also, 2 patients with postoperative fever were managed by antibiotherapy. The complication rate $(8 \%)$ was parallel to the findings in literature. . $^{13,14,17}$

Flexible ureteroscopy is one of the highly popular natural orifice surgeries. With its relatively lower morbidity and the use of natural orifices, this technique is considered first-line by patients and surgeons. The difference between rigid/semirigid and flexible ureteroscopies is that with rigid/semirigid instruments the operation is not feasible for the proximal side of the ureter; however, with flexible instruments, even though the stone migrates through the kidney, it can be followed. Besides these advantages, the small diameter of the instrument does not provide good vision so fragmented stones cannot be extracted unlike in the other methods. The operation may fail because of these factors. Proximal ureter stones $(>10 \mathrm{~mm})$ have a clearance rate of $77 \%$ to $85 \%$. These numbers decrease as the stone size increases. ${ }^{1,18,19}$ In this study, we had a success rate of $82 \%$. In the first 5 patients, the method failed. For the last 30 patients, the success rate was $95 \%$. The mean hospitalization was 1.1 days for URS

\begin{tabular}{|c|c|c|c|c|}
\hline $\begin{array}{l}\text { Grade of } \\
\text { complication }\end{array}$ & SWL (n=52) & $\begin{array}{l}\text { Laparoscopy } \\
\quad(n=51)\end{array}$ & RIRS (n=48) & $p$ value \\
\hline I & 1 & 1 & 1 & NS \\
\hline II & 2 & 2 & 1 & NS \\
\hline \multicolumn{5}{|l|}{ III } \\
\hline$A$ & - & - & - & \\
\hline B & 1 & 1 & - & $p<0.05$ \\
\hline IV & 0 & 0 & 0 & - \\
\hline V & 0 & 0 & 0 & - \\
\hline Total & $4(7.06 \%)$ & $4(7.86 \%)$ & 2 (4.11\%) & $p<0.05$ \\
\hline
\end{tabular}

SWL: shock wave lithotripsy; RIRS: retrograde intrarenal surgery; PNL: percutaneous nephrolithotomy.

group. We encountered a grade 1 ureteral laceration, which was easily managed by a pigtail stent. One patient had to be managed by antibiotherapy for $>38^{\circ} \mathrm{C}$ fever.

When these groups were compared for complication rates, RIRS seemed to be the group with the lowest complication rates $(p<0.05)$. SWL and laparoscopy seem to have similar rates of complication $(p=0.12)$.

To our knowledge, it is the first study to compare the results of laparoscopy, SWL and RIRS in ureteral stones. Our results showed that in management of patients with upper ureteral stones between 1 and $2 \mathrm{~cm}$, laparoscopy seems to be the most successful method based on its stone-free rates and acceptable complication rates. However, it should be kept in mind that this technique is an invasive method. When a less invasive method has to be the choice, SWL and flexible URS methods seem to have similar success and complication rates; however, SWL may span a few sessions and weeks, which should be considered in the cases with higher rate of obstruction. In the cases that require rapid treatment, flexible URS should be the first choice.

\section{Conclusion}

Proximal ureteral stones can be managed by various treatment options. These options include SWL, laparoscopy, and flexible URS. In our study, with high success and low complication rates, we determined that flexible ureteroscopy is the first-line and minimally invasive treatment; with larger stones and obstructed systems, laparoscopy may be a good alternative.

Competing interests: Dr. Ozturkm, Dr. Şener, Dr. Goktug, Dr. Gucuk, Dt. Nalbant and Dr. İmamoglu declare no competing financial or personal interests.

This paper has been peer-reviewed. 
Ozturk et al.

\section{References}

1. Turk C, Knoll T, Petrik A, et al. Guidelines on urolithiasis. European Association of Urology; 2012. http:// www.uroweb.org/gls/pdf/20_Urolithiasis_LR\%20March\%2013\%202012.pdf. Accessed October 15, 2013.

2. Khaladkar $S$, Modi J, Bhansali $M$, et al. Which is the best option to treat large $(>1.5 \mathrm{~cm})$ midureteric calculi? J Laparoendosc Adv Surg Tech A 2009;19:501-4. http://dx.doi.org/10.1089/lap.2008.0299

3. Karami H, Javanmard B, Hasanzadeh-Hadah A, et al. is It Necessary to Place a Double I Catheter After Laparoscopic Ureterolithotomy? A Four-Year Experience. J Endourol 2012;26:1183-6. http://dx.doi. org/10.1089/end.2012.0082

4. Research Randomizer. Social Psychology Network. http://www.randomizer.org/index.htm. Accessed October 15, 2013.

5. Segura JW, Preminger GM, Assimos DG, et al. Ureteral Stones Clinical Guidelines Panel summary report on the management of ureteral calculi. The American Urological Association. J Urol 1997;158:1915-21. http://dx.doi.org/10.1016/S0022-5347(01)64173-9

6. Singh I, Gupta NP, Hemal AK, et al. Efficacy and outcome of surgical intervention in patients with nephrolithiasis and chronic renal failure. Int Urol Nephrol 2001;33:293-8. http://dx.doi. org/10.1023/A:1015230510071

7. Liong ML, Clayman RV, Gittes RF, et al. Treatment options for proximal ureteral urolithiasis: review and recommendations. J Urol 1989;141:504-9.

8. Frattini A, Ferretti S, Arena F, et al. Extracorporeal shockwave lithotripsy (ESWL). Our experience. Acta Biomed Ateneo Parmense 1995;66:5-10.

9. Jang YB, Kang KP, Lee $S$, et al. Treatment of subcapsular haematoma, a complication of extracorporeal shock wave lithotripsy (ESWL), by percutaneous drainage. Nephrol Dial Transplant 2006;21:1117-8. http://dx.doi.org/10.1093/ndt/gfk002
10. Hidalgo Pardo $F$, Conte Visús A, Rebassa Lull M, et al. Rectorrhage as an unusual extrarenal complication after ESWL. Actas Urol Esp 1998;22:366-8.

11. Kastelan Z, Derezic D, Pasini J, et al. Rupture of the spleen and acute pancreatitis after ESWL therapy: a rare complication. Aktuelle Urol 2005;36:519-21. http://dx.doi.org/10.1055/s-2005-870971

12. Yuruk E, Binbay $M$, Sari $E$, et al. A prospective, randomized trial of management for asymptomatic lower pole calculi. J Urol 2010;183:1424-8. http://dx.doi.org/10.1016/i.juro.2009.12.022

13. Picozzi SC, Ricci C, Gaeta M, et al. Urgent shock wave lithotripsy as first-line treatment for ureteral stones: a meta-analysis of 570 patients. Urol Res 2012;40:725-31. http://dx.doi.org/10.1007/ s00240-012-0484-0. Epub 2012 Jun 15.

14. Zanetti G. Ureteral stones: SWL treatment. Arch Ital Urol Androl 2011;83:10-3.

15. Raboy A, Ferzli GS, loffreda R, et al. Laparoscopic ureterolithotomy. Urology 1992;39:223-5. http:// dx.doi.org/10.1016/0090-4295(92)90294-7

16. Gaur DD. Laparoscopic operative retroperitoneoscopy: use of a new device. J Urol 1992;148:1137-9.

17. Lopes Neto AC, Korkes F, Silva JL 2nd, et al. Prospective randomized study of treatment of large proximal ureteral stones: extracorporeal shock wave lithotripsy versus ureterolithotripsy versus laparoscopy. J Urol 2012;187:164-8. htrp://dx.doi.org/10.1016/i.juro.2011.09.054

18. Karlsen SJ, Renkel J, Tahir AR et al. Extracorporeal shockwave lithotripsy versus ureteroscopy for 5to 10-mm stones in the proximal ureter: Prospective effectiveness patient-preference trial. J Endourol 2007;21:28-33. http://dx.doi.org/10.1089/end.2006.0153

19. Degirmenci $T$, Gunlusoy B, Kozacioglu Z, et al. Outcomes of Ureteroscopy for the Management of Impacted Ureteral Calculi With Different Localizations. Urology 2012;80:811-5. http://dx.doi.org/10.1016/i. urology.2012.05.007

Correspondence: Dr. Nevzat Can Sener, Ministry of Health, Ankara Dışkapı Yıldırım Beyazit Education and Research Hospital, Department of Urology, Ankara, Turkey; cansener14@gmail.com 